\title{
SEM AND ENERGY DISPERSIVE X-RAY EVALUATION OF SMEAR LAYER REMOVAL USING STANDARD AND INNOVATIVE IRRIGATION PROTOCOLS: A COMPARATIVE IN VITRO STUDY
}

\author{
Lamia Ahmed Ibrahim* and Hala Fayek Khalil**
}

\begin{abstract}
Aim: Compare efficacy of Dual Rinse HEDP with sodium hypochlorite to sodium hypochlorite in combination with a finishing rinse with $17 \%$ EDTA solution to remove the smear layer.

Materials and methods: Sixteen human maxillary single-rooted, single canalled sound premolars were used. Specimens were distributed into 2 groups and labeled according to irrigation protocol used. Each group consisted of 8 specimens: Group $150 \% \mathrm{NaOCl}$ followed by $17 \%$ EDTA. Group 2 The Dual Rinse ${ }^{\circledR}$ HEDP mixed with $50 \% \mathrm{NaOCl}$. Roots were prepared for SEM appraisal. The smear layer was assessed and scored. Energy-dispersive X-ray analysis was used to analyze the inorganic chemical structure of the treated dentin of the two tested groups. Data were tabulated and statistically analyzed.Kruskal-Wallis test tailed by Mann-Whitney test compared mean scores between irrigant solutions and root regions groups. Chi-square test compared the frequency distribution of scores between different groups.

Results: Smear layer was reduced with The Dual Rinse ${ }^{\circledR}$ HEDP group. Groups exhibited a statistically significant difference in mean scores within apical region and no statistically significant difference within coronal and middle regions. Groups showed a statistically significant difference in frequency distribution of scores within coronal and apical regions. A statistically significant difference in scores frequency existed in between the three root regions within $\mathrm{NaOCl}+\mathrm{EDTA}$ group While no difference was present in between the different regions within Dual Rinse ${ }^{\circledR}$ HEPD group. Energy- dispersive X-ray analysis showed lower peaks of calcium in the Dual Rinse ${ }^{\circledR}$ HEDP.
\end{abstract}

Conclusion: The Dual Rinse ${ }^{\circledR}$ HEDP can be used as one step irrigant.

\footnotetext{
* Department of Endodontics, Faculty Of Dentistry, Fayoum University

** Department of Endodontics, Faculty Of Dentistry, The British University In Egypt, El Shrouk, Cairo.
} 


\section{INTRODUCTION}

Smear layer is created by instrumenting the root canal during cleaning and shaping and is formed of microorganisms, organic materials and bits of irrigant solutions. The smear layer clings tenaciously to the instrumented root canal walls obscuring the dentinal tubules. The presence of this layer prevents the flow of irrigants and root canal sealers through the dentinal tubules; thus, it would rather be removed than left on the dentinal wall ${ }^{[1]}$.

Certain chemical agents, at various concentrations such as EDTA, phosphoric acid and citric acid can be used to abolish this layer.

Elimination of smear layer is explained as the accomplished removal of blockade between the obturation material and dentin which then potentiates the diffusion of irrigants and consequently root canal sealers into dentinal tubules leading to decreased microleakage with sealers and affect the bonding of the resin based ones ${ }^{[2]}$. Root canal irrigation is essential for positive root canal treatment to eliminate residual pulp tissue, bacterial biofilm and aid in dentin conditioning so as to create a leakageproof seal after completion of root canal treatment.

Sodium hypochlorite is considered the most popular irrigant. It has almost all the properties required for root canal cleanliness except for the decalcification of the hard tooth tissue.

Using ethylenediaminetetraacetic acid (EDTA) in conjunction with sodium hypochlorite $(\mathrm{NaOCl})$ solution has gained satisfaction and is recommended as an effective irrigation regimen ${ }^{[3]}$.

Dual Rinse HEDP as an irrigation additive was recently introduced; it has been found to immediately give $\mathrm{NaOCl}$ solution a mildly decalcifying component. The $\mathrm{NaOCl}$ and the Dual Rinse HEDP together in a single irrigating solution not only simplifies chemical root canal cleaning and dentin conditioning for the subsequent root canal fillings, but also it shortens the time required for effective root canal irrigation.

\section{AIM OF THE STUDY}

The present study was designed to compare the efficacy of an innovative additive namely the Dual Rinse HEDP to be mixed with sodium hypochlorite that is regularly used for root canal irrigation on smear layer removal to the standard irrigation protocol of using sodium hypochlorite tailed by a finishing rinse with 17\% EDTA solution.

\section{MATERIALS AND METHODS}

This study has the ethical clearance from the research ethics committee Faculty Of Medicine Fayoum University (R-21 12/5/2020), the study was conducted over the period a week after teeth acquiring. The scanning Electron Microscope pictures and The energy dispersive $\mathrm{x}$-ray analysis were done in the Advanced Research center Faculty of Science, Fayoum University. The study was conducted over the period a week after teeth acquiring.

\section{Sample selection}

Sixteen human maxillary single rooted, single canalled sound premolars, extracted owed to orthodontic, periodontal or prosthetic purposes, were utilized for the present study.

The teeth selected for this study were required to exhibit straight roots, mature root apices and patent root canals, and similar anatomic characteristics without any anatomical variations with no detectible root caries and no signs of external or internal resorption, previous root canal treatment or calcifications.

\section{Sample size calculation:}

$\mathrm{G}^{*}$ Power 3.1.9.4 Software was used for using sample size calculation based on data obtained from the study by Takeda et al. $1999^{[4]}$. It was anticipated that a minimum sample size of 6 specimens per group for a total of 12 specimens would be essential for an effect size of 2.01 with an alpha error of 0.05 and a power beta of 0.80 to achieve $95 \%$ confidence of a true difference between the groups. Sample size 
was increased by $30 \%$ to 8 specimens per group for a total of 16 specimens to compensate for any specimen defects.

\section{Sample preparation}

Selected teeth were completely cleaned and washed under tap water to remove the remaining soft tissue on the tooth surface to standardize the root length, a marking was made $18 \mathrm{~mm}$ from the root apex and later the tooth structure above the marking was cut using a diamond disc.

The teeth were stored in distilled water and $2.5 \% \mathrm{NaOCl}$ in proportion of 10:1 till the time of the experiment.

\section{Root Canal Preparation}

Access cavities were prepared and root canals were located with endodontic probe (Odous, Belo Horizonte, Brazil).

Working length (WL) was determined presenting \#15 K-file (Dentsply Maillefer, Ballaigues, Switzerland) in the canal until it was detectable through the apical foramen. Working length was established $1 \mathrm{~mm}$ short of the measured length.

The specimens were casually distributed into two groups each of 8 specimens each.

\section{Group 1}

For the canal instrumentation after negotiating the canals with size 10 and $15 \mathrm{~K}$-files, the Oneshape (Micro Mega, Besancon, France) rotary instruments were used to prepare the root canals.

During all preparation procedures, irrigation was achieved with a 27 gauge side venting irrigation needle (Vista Dental, Racine, WI, USA) coupled to the $5 \mathrm{~mL}$ disposable syringe. One $\mathrm{mL}$ of $2.5 \%$ $\mathrm{NaOCl}$ was used for irrigation three times for the duration of 30 seconds each and irrigation with 1 $\mathrm{mL}$ of $17 \%$ EDTA (Lenza Farmaceutica, Divisao Odontologica, Belo Horizonte, Brazil) was also done as a final flush.

\section{Group 2}

According to manufacturer's instructions, The Dual Rinse ${ }^{\circledR}$ HEDP was mixed with $2.5 \% \mathrm{NaOCl}$ immediately before the start of the experiment.

Irrigation was done with $1 \mathrm{~mL}$ of the fresh mix three times during instrumentation for the duration of 30 seconds each.

Paper points (Dentsply Maillefer, Ballaigues, Switzerland) were used to dry root canals of both groups After instrumentation.

Teeth were grooved with a diamond disk (4217, DFS, Riedenburg, Germany) and split longitudinally using chisel and mallet. A half of each tooth was arbitrarily chosen and placed using carbon tape in a circular metal stub of measures $10 \mathrm{~mm}$ diameter and $5 \mathrm{~mm}$ height. Then the samples were gold sputtered for SEM evaluation (JSM 6460 LV; JEOL, Tokyo, Japan). The images were all performed in blindness of the group tested.

Evaluation was done at one point in each section in the three regions canal cervical, middle and apical under 100×magnification.

Presence or absence of smear layer was assessed by two experienced examiners according to the following scores described by Takeda et al [4] illustrated in table (1) and the evaluation was scored blindly by two separate well experienced viewers.

TABLE (1) Scoring System by Takeda et al for assessment of smear layer removal

\begin{tabular}{|c|l|}
\hline Score & Content \\
\hline $\mathbf{0}$ & $\begin{array}{l}\text { No smear layer, open dentinal tubules, smear layer } \\
\text { was completely removed or melted }\end{array}$ \\
\hline $\mathbf{1}$ & $\begin{array}{l}\text { Moderate smear layer, outlines of dentinal tubules } \\
\text { observable, removed or melting in some areas }\end{array}$ \\
\hline $\mathbf{2}$ & $\begin{array}{l}\text { Thin smear layer covering the surface outline of } \\
\text { dentinal tubules which were not discernible, and } \\
\text { the location of the tubule was indicated by a crack, } \\
\text { scattered laser removed or melting }\end{array}$ \\
\hline $\mathbf{3}$ & $\begin{array}{l}\text { Heavy smear layer, outlines of tubules obliterated, no } \\
\text { visible laser removed or melting }\end{array}$ \\
\hline
\end{tabular}


Energy-dispersive X-ray analysis data was used to analyze the chemical structure (only inorganic components) of the dentin surface treated using the two different protocols as indicated in the two tested experimental groups. Two samples from each group were randomly selected and elementally analysed by energy-dispersive X-ray spectroscopy (EDX) integrated into the scanning electron microscope.

Mineral analysis was carried out such that the EDX analyzer was directed towards the center of the SEM image of the selected samples. Chemical elements values of the samples were conveyed as basic elements of the tooth mainly oxygen, calcium, phosphorus, magnesium and chlorine.

Each chemical element amount was compared in the two experimental groups. The mineral contents of samples were computed founded upon weight proportion in the EDX software. Data was assessed as descriptive statistics.

\section{Statistical analysis}

Data were tabulated and statistically analyzed. The level of significance was set at 0.05.Statistical analysis was performed using IBM SPSS Statistics Version 2.1 for Windows. Data were introduced as mean, standard deviation (SD) and frequencies (n). The significance level was set at $\mathrm{P} \leq 0.05$. KruskalWallis test tailed by Mann-Whitney test were used to compare mean scores between irrigant solutions and root regions groups. Chi-square test was conducted to compare the frequency distribution of scores between different groups.

\section{RESULTS}

\section{Scanning electron microscope evaluation of smear layer}

A highly significant reduction in smear layer was witnessed in The Dual Rinse ${ }^{\circledR}$ HEDP group compared to the $\mathrm{NaOCl}+$ EDTA group.

Results exhibited no statistically significant difference in mean scores between $\mathrm{NaOCl}+$ EDTA and Dual Rinse ${ }^{\circledR}$ HEPD groups within coronal and middle regions as opposed by the apical region.
Results also exhibited a statistically significant difference in frequency distribution of scores between both groups within coronal and apical regions and not within middle region as shown in table (2).

TABLE (2): Comparison of frequency of grading scores between irrigant solutions within each region.

\begin{tabular}{|c|c|c|c|c|c|c|}
\hline \multirow{2}{*}{$\begin{array}{l}\text { Root } \\
\text { region }\end{array}$} & \multirow{2}{*}{$\begin{array}{l}\text { Irrigant } \\
\text { solution }\end{array}$} & \multicolumn{4}{|c|}{ Scores } & \multirow{2}{*}{ P-value } \\
\hline & & $\mathbf{0}$ & 1 & 2 & 3 & \\
\hline \multirow{2}{*}{ 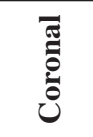 } & NaOCl+EDTA & 0 & 8 & 0 & 0 & \multirow[b]{2}{*}{0.001} \\
\hline & $\begin{array}{c}\text { Dual Rinse }{ }^{\circledR} \\
\text { HEPD }\end{array}$ & 4 & 0 & 2 & 2 & \\
\hline \multirow{2}{*}{$\begin{array}{l}\stackrel{0}{ٍ} \\
\stackrel{0}{*}\end{array}$} & NaOCl+EDTA & 0 & 8 & 0 & 0 & \multirow[b]{2}{*}{0.069} \\
\hline & $\begin{array}{c}\text { Dual Rinse }{ }^{\circledR} \\
\text { HEPD } \\
\end{array}$ & 2 & 4 & 2 & 0 & \\
\hline \multirow{2}{*}{ 苞 } & NaOCl+EDTA & 0 & 4 & 0 & 4 & \multirow[b]{2}{*}{0.005} \\
\hline & $\begin{array}{c}\text { Dual Rinse } \AA \\
\text { HEPD } \\
\end{array}$ & 6 & 2 & 0 & 0 & \\
\hline
\end{tabular}

\section{Significance level at $\mathbf{P} \leq \mathbf{0 . 0 5}$}

It has also been shown that there was a statistically significant difference in scores frequency between the three root regions within $\mathrm{NaOCl}+\mathrm{EDTA}$ group. While there was no statistically significant difference in scores frequency between the different regions within Dual Rinse ${ }^{\circledR}$ HEPD group as shown in table (3). Sample photomicrographs from both groups along the three regions are shown in Fig. (1)

TABLE (3): Comparison of frequency of grading scores between irrigant solutions within each region.

\begin{tabular}{|c|c|c|c|c|c|c|}
\hline \multirow{2}{*}{$\begin{array}{l}\text { Irrigant } \\
\text { solution }\end{array}$} & \multirow{2}{*}{$\begin{array}{l}\text { Root } \\
\text { region }\end{array}$} & \multicolumn{4}{|c|}{ Scores } & \multirow{2}{*}{ P-value } \\
\hline & & 0 & 1 & 2 & 3 & \\
\hline \multirow{3}{*}{$\mathrm{NaOCl+EDTA}$} & Coronal & 0 & 8 & 0 & 0 & \multirow{3}{*}{0.008} \\
\hline & Middle & 0 & 8 & 0 & 0 & \\
\hline & Apical & 0 & 4 & 0 & 4 & \\
\hline \multirow{3}{*}{$\begin{array}{c}\text { Dual Rinse }{ }^{\circledR} \\
\text { HEPD }\end{array}$} & Coronal & 4 & 0 & 2 & 2 & \multirow{3}{*}{0.062} \\
\hline & Middle & 2 & 4 & 2 & 0 & \\
\hline & Apical & 6 & 2 & 0 & 0 & \\
\hline
\end{tabular}

Significance level at $P \leq 0.05$ 


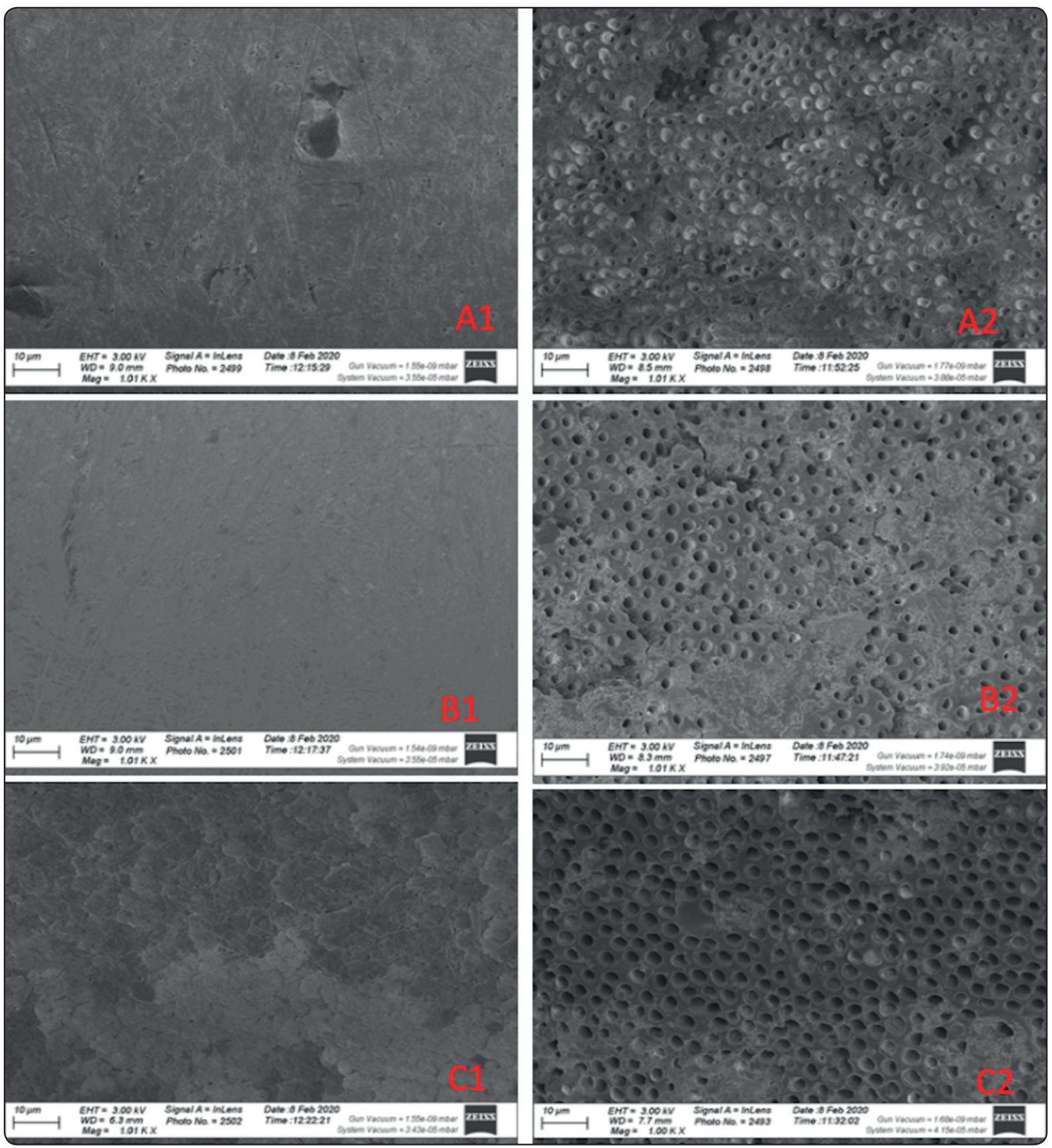

Fig. (1) Showing SEM photomicrographs of magnifications 100x at different regions with smear layer assessed according to Takeda et al

Coronal (A1) A sample from Group 1 with score 1 (A2) A sample from From Group 2 with score 0

Middle (B1) A sample from Group 1with score 1 (B2) A sample from Group 2 with score 1

Apical (C1) A sample from Group1 with score 3 (C2) A sample from Group 2 with score 0 


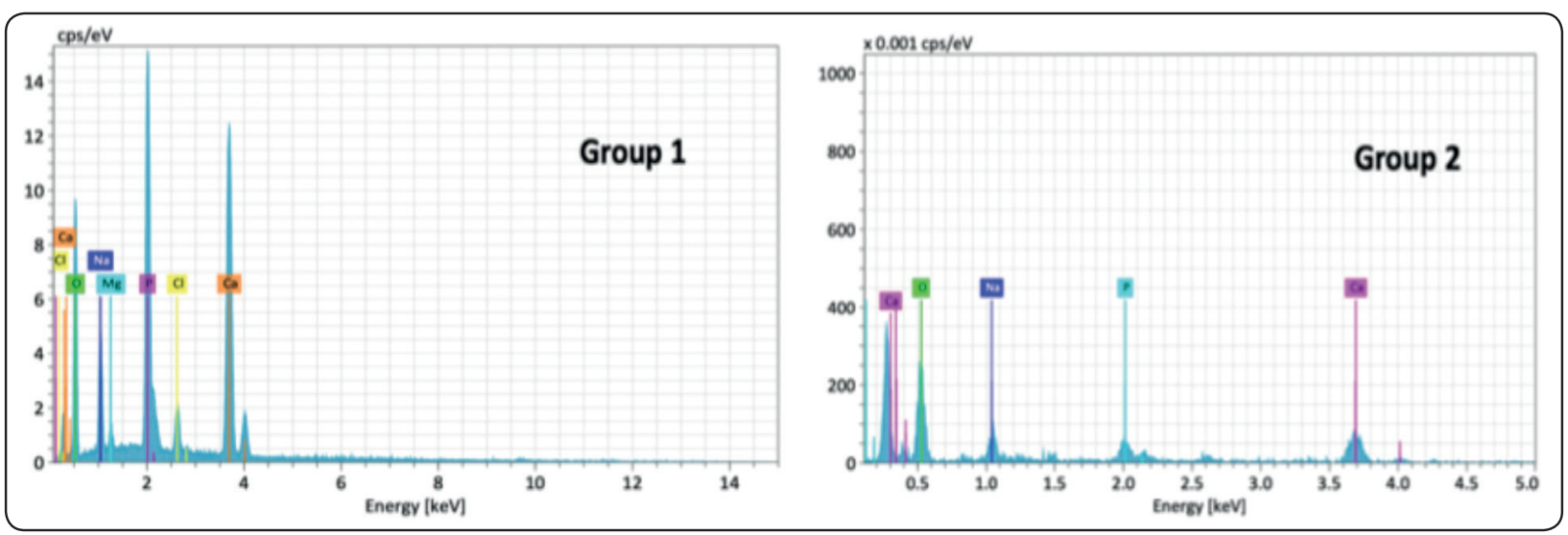

Fig. (2): Scanning electron microscope images with energy dispersive X-ray spectroscopic microanalysis evaluating the chemical composition of Group 1 samples treated with $\mathrm{NaOCl} / \mathrm{EDTA}$ protocol and Group 2 samples treated with Dual Rinse ${ }^{\circledR}$ HEDP

\section{Energy Dispersive X ray analysis}

High intensity peaks of calcium were detected in the $\mathrm{NaOCl} / \mathrm{EDTA}$ group (Group 1) in comparison to the The Dual Rinse ${ }^{\circledR}$ HEDP group (Group 2) as shown in Fig. (2)

\section{DISCUSSION}

The smear layer encompass both organic and inorganic components like dentin particles, pulp tissue residues, microorganisms and blood cells. $\mathrm{Nu}-$ merous researchers suggested that the smear layer compromises the sealing ability of root canal fillings, since it is a porous and a weak layer separating the obturation material and the dentin wall preventing the adhesion of any dental materials.

Several methods have been employed for the smear layer removal including chemical agents, ultrasonics, and laser irradiations ${ }^{[5]}$.

To ensure the most efficient cleaning of the root canal system and maximum disinfection, it is recommended to flood the root canals with $\mathrm{NaOCl}$ solution during mechanical preparation. This also reduces mechanical stress on rotary instruments. In addition to $\mathrm{NaOCl}$ solution, which is primarily used for disinfection and deproteinization; decalcifying solutions have also been recommended, which contain chelators, i.e. complexing agents: the first used was ethylenediamine tetraacetate (EDTA) ${ }^{[6-8]}$.

Using ethylenediaminetetraacetic acid (EDTA) and sodium hypochlorite $(\mathrm{NaOCl})$ solution has gotten wide approval and has been recommended for removing most components of smear layer.

The smear layer removal action of EDTA is attributed to its chelation action on the root canal dentin. It has been shown that $17 \%$ EDTA can demineralize dentin. Numerous studies reported using EDTA alone or in alternation with $\mathrm{NaOCl}$ can cause excessive erosion of root canal dentin. Many studies also reported that it may have a unfavorable effect on the main inorganic constituents of the dental hard tissue calcium ( $\mathrm{Ca}$ ) and phosphorus $(\mathrm{P})$ and can reduce the $\mathrm{Ca} / \mathrm{P}$ ratio of the root canal dentin; Which in turn changes inherent properties of root canal dentin such as permeability, microhardness, and solubility. It may also negatively affect the adaptation properties of root canal sealers.

Moreover the currently used protocol has the problem that EDTA reacts immediately with $\mathrm{NaOCl}$ in which case, the unique cleanliness of root canals achieved by $\mathrm{NaOCl}$ irrigation is usually lost. To avoid that, a finishing rinse with $\mathrm{NaOCl}$ is usually carried out mainly to stop the uncontrollable erosion and softening of root canal dentin; thus elongating the irrigation protocol ${ }^{[9-12]}$. 
The present study tested a newly introduced material on the dental market and compared its ability to abolish the smear layer in comparison to the most used standard irrigation protocol. The newly introduced material shortens the regular irrigation protocol to one step irrigation; it was mainly introduced as a biocompatible decalcifying agent that can be combined with $\mathrm{NaOCl}$ at least for a short time i.e. for the duration of a treatment.

HEDP is mainly used in water and waste-water treatment, detergents and cleaning agents, cosmetics industry, as a drug, and as an agent to inhibit corrosion and scaling.

Like EDTA and citric acid, HEDP is a chelator. However, it forms somewhat weaker complexes with calcium than the previously mentioned chemicals.

HEDP is used as an additive in the $\mathrm{NaOCl}$ irrigating solution and therefore during the entire endodontic treatment. The calcium ions are thus continuously complexed so that the alternating irrigation schemes can be completely eliminated. With this concept, the smear layer and debris are not removed after mechanical root canal preparation, but instead their formation is prevented as stated by some authors ${ }^{[13-15]}$.

Scientific literature had multiple Reports of techniques for recognition and analysis of chemical elements of the tooth structure ${ }^{[16-18]}$.

Several processes are employed to measure the mineral content of teeth including proton-induced $\mathrm{X}$-ray emission, atomic absorption spectrophotometry, laser ablation-inductively, flame photometry, energy dispersive X-ray elemental analysis, electro thermal vaporization or coupled plasma-mass spectrometry ${ }^{[19-21]}$.

In the present study, energy-dispersive X-ray analysis was used to analyze the chemical structure (only inorganic components) of the dentin surface treated using the two different protocols as indicated in the two tested experimental groups. EDX analy- sis is a good methodical tool to assess the mineral composition of dentin surface by allowing analysis at high resolution, without any sample damaging ${ }^{[22]}$.

The principle of The EDX analysis encompass clashing electrons coming from an external source to hit the atoms of the sample surface causing dislodging of electrons from orbits of these atoms to produce electrons vacancies. Electrons from outer shells fall to fill these vacancies with emission of characteristic X-rays which are measured by a computer-aided program. This technique can give meticulous evidence about the shape, configuration and mass of particles ${ }^{[23,24]}$.

EDX analysis provided qualitative and semiquantitative measurements of the chemical elements in each sample: oxygen, calcium, phosphorus, magnesium and chlorine.

$\mathrm{Ca}, \mathrm{P}$ and low amounts of $\mathrm{Mg}$ are considered to affect the mineralization process ${ }^{[25]}$.They are also the leading elements for construction of hydroxyapatite crystals in dental hard tissues. Intracanal irrigants as EDTA and sodium hypochlorite may lead to a change in the $\mathrm{Ca}$ level and lessening of the $\mathrm{Ca} / \mathrm{P}$ ratio ${ }^{[26,27]}$.

In the current study, EDTA and sodium hypochlorite were used on one group and the The Dual Rinse ${ }^{\circledR}$ HEDP was used on the second experimental group. A decline of the $\mathrm{Ca}$ levels and $\mathrm{Ca} / \mathrm{P}$ ratios was perceived in The Dual Rinse ${ }^{\circledR}$ HEDP group as opposed to the high intensity of peaks for Ca spotted in the $\mathrm{NaOCl} / \mathrm{EDTA}$ group.

The study showed that the $\mathrm{NaOCl} /$ EDTA group exhibited increased $\mathrm{Ca}$ level and $\mathrm{Ca} / \mathrm{P}$ ratio of the root canal dentin when these irrigants were of choice to be used during the canal preparation. This comes in accordance with the continuous chelation performed by the later mix leading to less pronounced calcium peaks alongside a high number of open dentinal tubules detected in the samples of its experimental group. 
In summary for this research, results of this study disclosed that the novel material induced better chelation of the root canal dentin as well as better removal of the smear layer leading to a bigger proportion of open dentinal tubules aiding better sealer penetration and consequently better adaptability, sealing and leakage resistance necessary to the three dimensional seal required for a successful root canal therapy.

Nevertheless, further research is necessary to comprehend the mechanism behind the precise cause of this dissimilarity between the two groups and if the Dual Rinse ${ }^{\circledR}$ HEDP as a newly introduced irrigant affect the inherent properties on root canal dentin.

\section{Highlight key point}

- Dual Rinse ${ }^{\circledR}$ HEDP showed a great potential as an irrigant solution to replace the normal protocol of irrigation for smear layer removal.

- Dual Rinse ${ }^{\circledR}$ HEDP effect for smear layer removal extended along the three regions coronal, middle and apical.

- Dual Rinse® HEDP had an effective chelating action on Dentin.

\section{REFERENCES}

1. Torabinejad M, Handysides R, Khademi AA, Backland LK. Clinical implications of the smear layer in endodontics: a review. Oral Surg Oral Med Oral Pathol Oral Radiol Endod 2002;94:658-66.

2. Mello I, Robazza CR, Antoniazzi JH, Coil j. Influence of different volumes of EDTA for final rinse on smear layer removal. Oral Surg Oral Med Oral Pathol Oral Radiol Endod 2008;106:40-3.

3. Zehnder M. Root canal irrigants. J Endod 2006;32:389-98.

4. Takeda FH, Harashima T, Kimura Y, et al. A comparative study of the removal of smear layer by three endodontic irrigants and two types of laser. Int Endod J 1999;32:32-9.

5. Violich DR, Chandler NP. The smear layer in endodontics - A review. Int Endod J 2010;43:2-15
6. Boessler C, Peter's OA, Zehnder M. Impact of lubricant parameters on rotary instrument torque and force. J Endod 2007; 33:280-283.

7. Gazzaneo I, Vieira GCS, Pérez AR, Alves FRF, Goncalves LS, Mdala I et al.,. Root canal disinfection by single and multiple-instrument systems: Effects of sodium hypochlorite volume, concentration, and retention time. J Endod 2019;45:736-741.

8. Zehnder M. Root canal irrigants. J Endod 2006;32:389398.

9. Quoted from: Zollinger A, Mohn D, Zeltner M, Zehnder M. Short term storage stability of $\mathrm{NaOCl}$ solutions when combined with Dual Rinse HEDP. Int Endod J 2018;51:691-696.

10. Boessler C, Peter's OA, Zehnder M. Impact of lubricant parameters on rotary instrument torque and force. J Endod 2007; 33:280-283.

11. DeDeus G, Souza EM, Marins JR, Reis C, Paciornik S, Zehnder M. Smear layer dissolution by peracetic acid of low concentration. Int Endod J 2011;44: 485-490.

12. Lottanti S, Gautschi H, Sener B, Zehnder M. Effects of ethylene diaminetetraacetic, etidronic and peracetic acid irrigation on human root dentine and the smear layer. Int Endod J 2009; 42:335-343.

13. Morago A, OrdinolaZapata R, FerrerLuque CM, Baca P, Ruiz- Linares M, AriasMoliz MT. Influence of smear layer on the antimicrobial activity of a sodium hypochlorite/ etidronic acid irrigating solution in infected dentin. J Endod 2016;42: 1647-1650.

14. Neelakantan P, Nandagopala M, Shemesh H, Wesselink $\mathrm{P}$. The effect of root dentin conditioning protocols on the pushout bond strength of three calcium silicate sealers. Int J Adhes Adhes 2015; 60:104-108.

15. Neelakantan P, Varughese AA, Sharma S, Subbarao CV, Zehnder M, DeDeus G. Continuous chelation irrigation improves the adhesion of epoxy resinbased root canal sealer to root dentine. Int Endod J 2012; 45:1097-1102.

16. Ari H, Erdemir A. Effects of endodontic irrigation solutions on mineral content of root canal dentin using ICP-AES technique. J Endod 2005;31:187-9.

17. Alhadi D., H Al-Rawi N., Jaber F., Agah M. and Saeed M. Smear layer removal and ultra morphological changes of root canal dentin induced by erbium, chromium: Yttriumscandium-gallium-garnet laser. J Res Dent 2016; 4: 48-54. 
18. Ber_es F, Isaac J, Mouton L, et al. Comparative physicochemical analysis of pulp stone and dentin. J Endod 2016;42:432-438.

19. Arora, M., Hare, D., Austin, C., Smith, D. R., Doble, P. Spatial distribution of manganese in enamel and coronal dentine of human primary teeth. Science of the Total Environment 2011; 409:1315- 1319.

20. De Menezes Oliveira, M. A.H., Torres, C.P., Gomes-Silva, J. M., Chinelatti, M. A., De Menezes, F. C., Palma-Dibb, R. G., Borsatto, M. C. Microstructure and mineral composition of dental enamel of permanent and deciduous teeth. Microscopy Research and Technique 2010; 73: 572- 577.

21. Fischer, A., Wiechuła, D., Postek-Stefańska, L., Kwapuliński, J. Concentrations of metals in maxilla and mandible deciduous and permanent human teeth. Biological Trace Element Research 2009;132: 19- 26.

22. Sakoolnamarka, R., Burrow, M., Swain, M., Tyas, M. Microhardness and ca: $\mathrm{P}$ ratio of carious and Carisolv ${ }^{\mathrm{TM}}$ treated caries-affected dentine using an ultra micro-indentation system and energy dispersive analysis of x-rays-A pilot study. Australian Dental Journal 2005; 50: 246- 250.
23. Kaczmarek, E., Surdacka, A., Matthews Brzozowska, T., Miskowiak, B. Digital image analysis and visualization of early caries changes in human teeth. J Mater Sci 2005; 23, 551- 558 .

24. Ozalp, S., Tulunoglu, O. SEM-EDX analysis of brushing abrasion of chitosan and propolis based toothpastes on sound and artificial carious primary enamel surfaces. Int $\mathrm{J}$ Paediatr Dent 2014;24, 349- 357.

25. Sayin, T. C., Cehreli, Z. C., Deniz D., Akcay, A., Tuncel, B., Dagli, F., Kalayci, S . Time-dependent decalcifying effects of endodontic irrigants with antibacterial properties. J Endod 2009; 35: 280- 283.

26. Ballal, N. V., Mala, K., Bhat, K. S.. Evaluation of decalcifying effect of maleic acid and EDTA on root canal dentin using energy dispersive spectrometer. Oral Surgery, Oral Medicine, Oral Pathology, Oral Radiology 2011;112:78- 84.

27. Capar, I. D., Aydinbelge, H. A. Surface change of root canal dentin after the use of irrigation activation protocols: Electron microscopy and an energy-dispersive X-ray microanalysis. Microscopy Research and Technique 2013; 76: 893-896. 